\title{
PHARMACOGENETICS AND POLYMORPHISM: FUTURE TOOLS FOR OPTIMIZING THERAPEUTIC EFFICACY
}

\author{
ASADUL MAZID HELALI
}

Assistant Professor, Department of Pharmacology \& Therapeutics, Gonoshasthya Samajvittik Medical College. Dhaka, Bangladesh

\begin{abstract}
Individual variation in drug response is a major problem in clinical practice and drug development, which ranges from therapeutic failure to adverse drug reaction as well as drug interaction in multidrug therapy. Pharmacogenetics is relevant in this aspects and mainly concern with the study of genetic variation, which influence individuals' responses to drug. Again, polymorphism (variation) in the genes which are involved in encoding drug metabolizing enzymes, transporters of drug and ion channels can play role in the adverse drug reaction in an individual or can interfere with the therapeutic efficacy. By studying pharmacogenetics one can apply genotyping of polymorphic alleles that encodes drug metabolizing enzymes to identify individual's drug metabolism phenotype and correlating this knowledge to dosing or drug selection, avoidance of many adverse effect of drug and therapeutic failure is possible as well as economic burden to the patient will be reduced. It is true that one drug will not effective for everyone and everyone will not response to a single drug in a similar fashion. It is almost impossible to test every drug in whole population in respect of investment and time. From this point of view, pharmacogenetic screening, such as phenotying test can be useful to identify patients who have inherent risk factor for a specific adverse drug reaction. Recently pharmacogenetic testing is performed for only a few drugs e.g. mercaptopurine, thioguanine, azathriopine and tacrine and the facility is also available in a limited number of teaching hospital but the days are not so far, when it may be considered as unethical if pharmacogenetics test is not done routinely before prescribing a drug to a patient.
\end{abstract}

Key Words: Pharmacogenetics, Polymorphism, Pharmacogenetics based diagnostics (PGDX).

(Bangladesh J Physiol Pharmacol 2010; 26(1\&2) : 34-42)

\section{INTRODUCTION}

Drug comes to the market after having tested it is good. Even though it is thought to have passed the robust tests there is always a matter of concern for safety and effectiveness in a single individual. ${ }^{1}$ Drugs are tested in sample to be approved for the use and this has been the trend as well as the benchmark rules and regulation. The biggest concern would be that in almost all cases the sample is just a representation of the population. However, it is also practically impossible to test every drug in whole population from the perspectives of investment, and time. ${ }^{1}$ Therefore, there is an urgent need of an approach that can collate the safety and effectiveness concerns with each individual.

Newer concepts regarding this assembly are emerging such as the development of database resources, ${ }^{2,3}$ clinical pharmacogenetic assay, ${ }^{1}$ clinical pharmacogenomics. ${ }^{4}$ The development of database resources such as biomedical databases can link the concept and knowledge of genetics, polymorphism, drug, and disease. ${ }^{2,3}$ Clinical pharmacogenetic assay can

Address of Correspondence: Dr. Asadul Mazid Helali, Assistant Professor; Department of Pharmacology \& Therapeutics, Gonoshasthya Samajvittik Medical College. Dhaka, Bangladesh. E-mail: dr_nomaan@yahoo.com differentiate individuals prone to therapeutic failure or success. ${ }^{1}$ Clinical pharmacogenomics is powerful tool that can define disease more precisely, associate drug response to genetic markers, and predict adverse effects. ${ }^{4}$ About 50 years of pharmacogenetic (PGX) research has brought up the light of hope to build a successful drug therapy but for the incorporation of the successful concept of PGx there is still a need of concrete clinical recommendations on individualization of drug. ${ }^{5}$ Newer linking hypothesis can be generated to support the notion of PGx, polymorphism and therapeutic efficacy in a convenient fashion.

\section{Pharmacogenetics and polymorphism}

The word 'pharmacogenetics' was originally proposed by Friedrich Vogel in 1959 to describe studies of the genetic basis of therapeutics and it encompass genetics, pharmacology and biochemistry. 4,6 Similar word "pharmacogenomics" cover newer sciences of molecular biology, genomics and bioinformatics and their associated technologies. ${ }^{4}$

In early times haemolytic anaemia was seen in individuals lacking glucose-6-phosphate. ${ }^{7}$ The interest of Pharmacogenetics came into being in the 1950s with the realization of altered drug response as a 
consequence of gene based variation of enzyme activities in few compounds such as hemolysis caused by primaquine in glucose-6-phosphate dehydrogenase variants, peripheral neuropathy caused by isoniazid in poor acetylators, prolonged muscle relaxation caused by suxamethonium in cholinesterase deficient inheritants. ${ }^{8}$ In 1980s defective hydroxylation of debrisoquine was known to be due to CYP2D6 polymorphism. $^{7}$

The inter-individual common variation in the DNA sequence due to different nucleotides at a common position within a gene results in variable form of genes. If the variability is greater than $1 \%$ of a population then it is called genetic polymorphism. ${ }^{7,9}$ Preferentially $P G x$ describes the variability in pharmacokinetics, efficacy and toxicity of drugs based on genetic differences. ${ }^{5}$ The majority of identified PGx polymorphisms are in the drugmetabolizing enzymes. PGx polymorphisms do significantly occur at the level of drug transporters and targets. The so called "genome-based drug discovery" is getting more popularity these days that focuses in the identification of transporters and target proteins. ${ }^{9,10,11}$

The consequences of pharmacogenetic polymorphism in therapeutic efficacy are discussed in paragraphs ahead.

\section{Pharmacogenetic polymorphism in drug-meta- bolizing enzymes}

PGx polymorphism in drug-metabolizing enzymes is one of the major concerns for inter-individual variation in drug disposition. ${ }^{6}$ Drug-metabolizing enzymes catalyze phase I and II reactions. The Phase I metabolism (oxidation, reduction or hydrolysis) of most drugs is mainly catalyzed by cytochrome P450 enzymes (CYPs) to detoxifiy or to activate inactive prodrug. ${ }^{7}$ The phase I products, other reactive intermediates, or the parent compounds are mainly conjugated through the Phase II metabolic pathway catalyzed by enzymes such as UDPglucoronyltransferases (UGTs), N-acetyl transferases (NAT1 and NAT2), glutathione S-transferases, and sulfotransferases into more polar form to be excreted through bile and urine. $^{7}$ The essay explains polymorphism in light of CYPs.

CYP450s are responsible for more than $80 \%$ of all phase-I metabolism of clinically used drugs ${ }^{12}$ as well as many chemicals. Many adverse drug reactions and therapeutic failure are the consequences of the polymorphic forms of CYP450s. ${ }^{13}$ Polymorphic CYP450s (in particular, CYP2C9, CYP2C19 and CYP2D6) are responsible for approximately $40 \%$ of CYP450-mediated drug metabolism, making drug dosing problematic and in general, 4 phenotypes are identified namely poor metabolizers (PMs), intermediate metabolizers, extensive metabolizers (EMs), and ultrarapid metabolizers (UMs). ${ }^{13}$

\section{CYP2C9}

CYP2C9 is known to be involved with metabolism of up to $15 \%$ of all drug undergoing Phase-I metabolism. ${ }^{14}$ CYP2C9 can undergo significant polymorphism (up to $40 \%$ Caucasian populations are carriers of partially defective gene for CYP2C9) and is prominently involved in metabolism of drug with narrow therapeutic window such as phenytoin, (s)-warfarin and tolbutamide. ${ }^{14,15}$ The most common variant alleles Caucasians bear are CYP2C9*2 (Arg144Cys) and CYP2C9*3 (Ile359Leu) which occur significantly very less in African, Americans and Asian. 6

Explanation of Figure 1- Boxes is exons. Lines connecting the boxes are introns. Filled boxes are coding sequence, and empty, unfilled boxes are UTR (UnTranslated Region). Transcripts drawn above the chromosome (blue bar) are on the forward strand, while transcripts below are on the reverse strand. Red or gold transcripts are protein coding. A red transcript comes from either the Ensembl or VEGA/HAVANA project. A gold transcript is identical between Ensembl automated annotation and VEGA/Havana manual curation. Only human, mouse, and zebrafish will have gold transcripts. This transcript can be thought of as stable (unlikely to change), and is coloured gold. It is assigned a number beginning with 0 . A blue transcript is non-coding. The number next to the transcript name lets you know if the transcript came from Havana manual curation (numbers beginning with 0, e.g. MYO6-001) or Ensembl automatic annotation (numbers beginning with 2, e.g. MYO6-201). Merged transcripts begin with 0.16

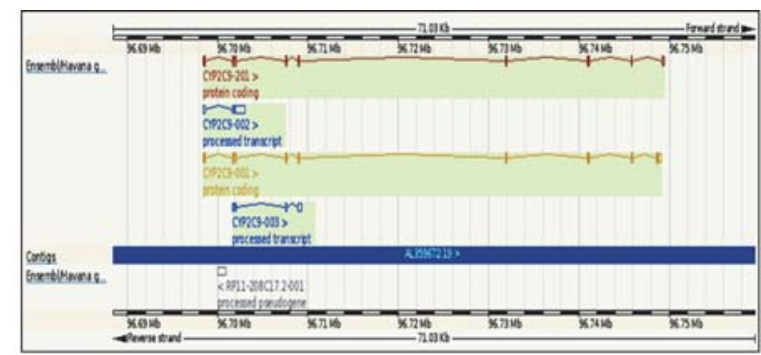

Figure 1: Transcript Diagram of CYP2C9 enzyme. ${ }^{16}$

Warfarin, mainly exists as R-warfarin and S-warfarin, those are differentially metabolised. S-warfarin is about three times as potent as R-warfarin when administered as a racemate. Two known allelic variants of cytochrome P450 CYP2C9 (the primary enzyme that catalyses the conversion of S-warfarin to inactive metabolites) are CYP2C9*2 and CYP2C9*3, those differ from the wild type CYP2C9*1 by a single amino acid substitution in each 
event. In case of CYP2C9*2, cysteine substitutes for arginine at aminoacid 144, while in CYP2C9*3, leucine substitutes for isoleucine at residue 359 of the wild type allele. ${ }^{15}$ This point mutation inturn results in $88 \%$ and $95 \%$ less efficient than the wild-type enzyme activity respectively.

Studies on CYP2C9 and (s)-warfarin have shown $30 \%$ to $60 \%$ (CYP2C ${ }^{*} 2$ ) and greater than $90 \%$ (CYP2C9*3) reduction in (S)-warfarin 7-hydroxylation leading to increased risk of bleeding. ${ }^{17}$ Another study conducted by Aithal et $\mathrm{al}^{15}$ demonstrated that individual requiring a low warfarin dose is six times more likely to be positive for one or more of the variant alleles (CYP2C9*2 and CYP2C9*3) compared with the general population and require a very low dose of drug. Thus impaired metabolism of a narrow therapeutic index drug like warfarin can affect patients' treatment outcome; that includes delayed discharges from the hospitals due to difficulty in induction, multiple visits to the clinics, and additional unnecessary investigations with a view to seeking warfarin sensitivity.

Another most commonly prescribed drug worldwide NSAIDs, along with the increased occurrence of inflammatory diseases (such as arthritis, osteoarthritis and other inflammatory-related condition) in elderly population, exclaims an intensives to consider CYP2C9 polymorphism in treatment strategies due to the imposed additional toxicity like as warfarin. ${ }^{18}$ An adverse effect of phenytoin has also been reported in a Japanese patients due to CYP2C9*4 allele. ${ }^{6,14}$

The knowledge of CYP2C9 genotype can promote therapeutic efficacy by risk identification of the patients when deciding on treatment with warfarin and they can be maintained with low dose warfarin or alternative drug therapy.

\section{CYP2C19}

The short- and long-term management of acidrelated intestinal disease largely depends on proton pump inhibitors (e.g. omeprazole/esomeprazole, Iansoprazole, pantoprazole, rabeprazole. Their elimination mainly occurs through the hepatic route and the polymorphic CYP2C19 is involved in their metabolism.

On the basis of genetic association with this enzyme activity, polymorphism of this enzyme is classified as rapid extensive metaboliser (REM), where mutation does not occur at alleles and enzyme generated from both the non-mutant alleles; IMs (intermediate metaboliser), where mutation occurs at one allele but other allele is normal and normal enzyme can be originitated from this allele; PMs (poor metaboliser), where both of the alleles have mutations and production of enzyme is not possible, thereby individual lacks of enzyme activity. ${ }^{20}$ It has also been reported that there are inter-ethnic variations are also present in the frequencies of PMs of CYP2C19; that is $2.5 \%$ in white Americans, $2 \%$ in African Americans, $3.5 \%$ in White Europeans, $4.8 \%$ in shona Zimbabweans, $19.8 \%$ in the Chinese-Han population, $13.4 \%$ in ChineseBai population, $12.6 \%$ in Korean and $18-22.5 \%$ in the Japanese populations. ${ }^{15}$ Consequently, these people will respond differently to a specific recommended dose of drug and drug metabolism will also differ from normal people. Treatment with anti-ulcer agents to reach a expected plasma level depends on the CYP2C19 phenotype; it has been studied that treatment with low dose omeprazole $(20 \mathrm{mg})$ in peptic ulcers, the cure rates were very low in EMs (25\%), higher in IMs (50\%) and complete in PMs (100\%) and long term treatment with omeprazole can be adjusted according to the CYP2C19 phenotype, ${ }^{21-23}$ furthermore, metabolic pathways also differ in PMs rather than other 2 groups; in PMs sulfoxidation is the main pathways for omeprazole metabolism and in EMs and IMs, that is hydroxylation. ${ }^{20}$ Thus, treatment with PPI for acid inhibition can vary at different CYP2C19 genotype groups because the healing rate in peptic ulcer ( $\mathrm{PU}$, target $\mathrm{pH}>$ or $=3$ ) and

Table-I

List of some important drugs that are the substrate for CYP2C9. ${ }^{19}$

\begin{tabular}{|c|c|c|c|c|}
\hline Adrenoceptor blockers & Antidepressants & Neuroleptics & Miscellaneous & Antiarrhythmic drugs \\
\hline Metropolol & Amitryptiline & Haloperidol & Codeine & Encainide \\
\hline Propanolol & Clomipramine & Perphenazine & Debrisoquine & Flecainide \\
\hline \multirow[t]{8}{*}{ Timilol } & Desipramine & Risperidone & Dextromethorphan & Perhexiline \\
\hline & Fluoxetine & Thioridazine & Phenformine & Propafenone \\
\hline & Fluvoxamine & Zudopenthixol & Tramadol & Sparteine \\
\hline & Imipramine & & & \\
\hline & Mianserine & & & \\
\hline & Nortryptiline & & & \\
\hline & Paroxeti n e & & & \\
\hline & Venlafaxine & & & \\
\hline
\end{tabular}


gastroesophageal reflux disease (GERD, target $\mathrm{pH}>$ or $=4$ ) and the eradication of Helicobacter pylori ( $\mathrm{Hp})$ depend on a long-lasting (> or $=16$ hours) and effective inhibition of acid secretion. Study with lansoprazole (+ amoxicillin, clarithromycin, metronidazole) the eradication rates were 100, 98 and 80\% in PM, IM and EM, respectively, and in patients with GERD treated with lansoprazole $(30 \mathrm{mg} /$ day) the healing rates after 8 weeks were much higher in PM (85 - 100\%) and IM (68 - 95\%) than in EM (46 - 77\%). ${ }^{24}$

Studies on different ethnic population for CYP2C19 polymorphism demonstrated that CYP2C19 activity is absent in PMs, common among Asians (10-25\%) than Caucasians (1-3\%) or African-Americans (4\%). ${ }^{23}$ Thus, a genotype-adjusted dosage regimen will improve therapeutic efficacy of PPIs.

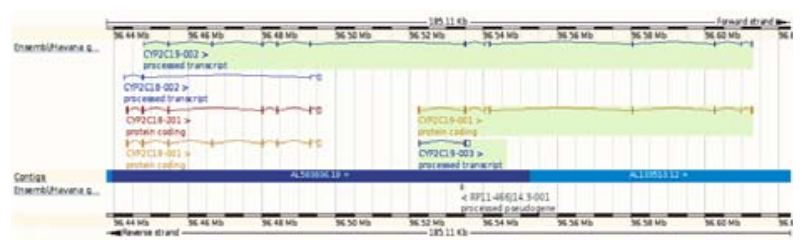

Fig.-2: Transcript Diagram of CYP2C19 enzyme. ${ }^{16}$

\section{Explanation of figure same as explanation of Figure 1.}

\section{CYP2D6}

CYP2D6 metabolises wide range of drugs such as antidepressants, antipsychotics, antiarrhythmics, âblockers, analgesics, and many others. The CYP2D6*4 allele occurs in higher frequency in Caucasians (22\%) (Incidence of PMs is 5\% to $10 \%$ ), $3.5 \%$ to $8 \%$ in African Americans, and around 1\% in Asian populations whereas CYP2D6*10 allele occurring at higher frequency in
Asians (50\%) ${ }^{6}$ and CYP2D6*17 allele at higher frequency in Africans, ${ }^{6}$ are responsible for decreased catalytic activity.

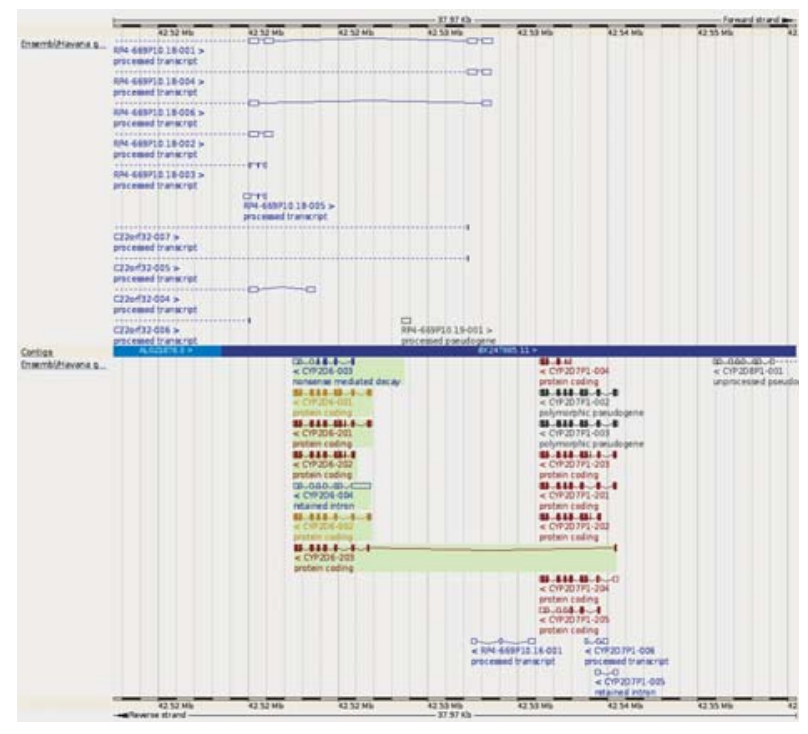

Fig.-3: Transcript Diagram of CYP2D6 enzyme. ${ }^{16}$

\section{Explanation of figure same as explanation of Figure 1}

The dosage of Nortriptyline can vary from $30 \mathrm{mg}$ to $50 \mathrm{mg}$ in PMs to 500mg in UMs depending upon the CYP2D6 phenotype. ${ }^{25}$ Codeine is ineffective in CYP2D6 PMs due to inability to convert into active morphine by CYP2D6 while in CYP2D6 UMs adverse effects can occur due to formation of high level of active morphine. ${ }^{26}$

Table-II

Some major enzyme polymorphism that has clinical relevance. ${ }^{8}$

\begin{tabular}{|c|c|c|c|}
\hline Enzymes & Frequency of Polymorphism & Drugs & Drug related Adverse events \\
\hline \multirow[t]{2}{*}{ CYP2C9 } & 14-28\% (heterozygotes) & Warfarin Phenyton & Haemorrahage Phenytoin Toxicity \\
\hline & $0.2-1 \%$ (homozygotes) & Losartan Glipizide & $\begin{array}{l}\text { Reduced antihypertensive effect } \\
\text { Hypoglycaemia }\end{array}$ \\
\hline \multirow[t]{2}{*}{ CYP2D6 } & 5-10\% (poor metabolizers). & Antiarrhythmics & Antipsychotics Opioids \\
\hline & $\begin{array}{l}\text { 1-10\% (ultra-rapid } \\
\text { metabolizers) }\end{array}$ & $\begin{array}{l}\text { Antidepressants } \\
\beta \text {-adrenoceptor } \\
\text { antagonist }\end{array}$ & $\begin{array}{l}\text { Proarrhythmicity Toxicity in poor } \\
\text { metabolisers, less efficacy in } \\
\text { ultrarapid metabolisers. Tardive } \\
\text { diskinesia. Inefficacy of codein as } \\
\text { analgesic, dependency.Increased } \\
\beta \text {-blockade activity. }\end{array}$ \\
\hline \multirow[t]{2}{*}{ CYP2C19 } & $3-6 \%$ (white) & Omeprazole & Higher efficacy when \\
\hline & 8-23\% (Asians) & Diazepum & $\begin{array}{l}\text { coadministered with clarithromycin } \\
\text { Prolonged sedation. }\end{array}$ \\
\hline $\begin{array}{l}\text { Plasma pseudo } \\
\text {-cholinesterase }\end{array}$ & $1-5 \%$ & Succinylcholine & Prolonged apnoea \\
\hline $\mathrm{N}$-acetyltransferase & 40-70\% (White) & Sulfonamides & Hypersensitivity Drug-induced \\
\hline (NAT) & 10-20\% (Asians) & Isoniazid & lupus erythematosus. \\
\hline $\begin{array}{l}\text { Thiopurine } \\
\text { methyltransferase }\end{array}$ & $0.3 \%$ & $\begin{array}{l}\text { Mercaptopurine } \\
\text { azathioprine }\end{array}$ & Myelotoxicity \\
\hline
\end{tabular}




\section{Pharmacogenetic polymorphism in drug transporters}

Transporters have become the major focus these days due to the increasing evidences that they are vital in drug absorption, disposition, toxicity and efficacy that is pharmacokinetic (PK) and pharmacodynamic (PD) profiles. $^{9-11}$ Moreover, transporter-mediated drug interactions have been augmented by many experiments so some extent. For example the nephrotoxic uptake of cidofovir through kidney epithelial human organic anion transporter (hOAT) has been reduced by Probenecid by inhibiting hOAT transporter. ${ }^{10}$ Alteration in PK and PD profiles can alter therapeutic profile of drug. Studies have shown that polymorphism of drug transporters are associated with alteration in PK-PD profile of clinically useful drugs. ${ }^{27}$ Some known substrates for transporters and their inhibitors are depicted in the table below to give a general outline of drug effect on transporter. The impact of polymorphism in drug transporter is discussed as it follows.

This article is focusing on the impact of polymorphism in three principal transporters ABC (ATPbinding cassette), OAT (organic anion transporter), OCT (organic cation transporter) and its consequence on therapeutic efficacy of drug as studies also has been carried more in these transporters. The representative figure of the principal transporters with the substitution with altered nucleotide leading to polymorphism of the transporters has been shown in figure 1, 2(a) and 2(b) where abbreviation suggests as BCRP: Breast cancerresistance protein; Exc: Extracellular; Inc: Intracellular; Mnb: Membrane; MRP: Multi-drug resistance-associated protein; NBD: Nucleotide-binding domain; P-gp: Pglycoprotein.

Table 3

General features of drug transporters. ${ }^{27}$

\begin{tabular}{|c|c|c|c|c|}
\hline $\begin{array}{l}\text { Name } \\
\text { (Gene } \\
\text { nomenclature) }\end{array}$ & $\begin{array}{l}\text { Chromosome } \\
\text { location }\end{array}$ & $\begin{array}{l}\text { Main location } \\
\text { (tissue or } \\
\text { sub cellular) }\end{array}$ & $\begin{array}{l}\text { Substrates } \\
\text { (clinically } \\
\text { useful drugs) }\end{array}$ & $\begin{array}{l}\text { Inhibitors } \\
\text { (clinically } \\
\text { useful drugs) }\end{array}$ \\
\hline $\begin{array}{l}\text { MDR1 orP-gp } \\
\text { (ABCB1) }\end{array}$ & $7 q 21.1$ & $\begin{array}{l}\text { Canalicular membrane } \\
\text { (hepatohyte) kidney, } \\
\text { enterocyte,Capillary } \\
\text { endothelial cells, } \\
\text { placenta. }\end{array}$ & $\begin{array}{l}\text { Anticancers (etoposide, } \\
\text { vinblastin, paclitaxel), } \\
\text { Antihypertensives (diltiazem, } \\
\text { Antiarrhythmatics losartan), } \\
\text { (digoxin,verapamil), Antibiotics } \\
\text { (Erythromycin, sparfloxacin), } \\
\text { Immunosuppressants (ciclosporin, } \\
\text { tacrolimus), Others(cimetidine, } \\
\text { fexofinadine, phenytoin, morphine, } \\
\text { ondensetron). }\end{array}$ & $\begin{array}{l}\text { Amitriptyline, } \\
\text { Diltiazem, } \\
\text { Propanolol, } \\
\text { Tamoxifen, } \\
\text { Spironolactone. }\end{array}$ \\
\hline MRP2 (ABCC2) & $10 q 24$ & Hepatocytes, kidney. & Bilirubin, glutathione, vinblastin. & $\begin{array}{l}\text { Ciclosporin, } \\
\text { Glibenclamide. }\end{array}$ \\
\hline $\begin{array}{l}\text { OATP-A, } \\
\text { OATP-B, } \\
\text { OATP-C. }\end{array}$ & $\begin{array}{l}12 p 12 \\
11 q 13\end{array}$ & $\begin{array}{l}\text { Cerebral cells, } \\
\text { intestine, } \\
\text { hepatocyte. }\end{array}$ & $\begin{array}{l}\text { Thyroid hormone, } \\
\text { prostaglandin E2, } \\
\text { fexofenadine, methotrexate, } \\
\text { rifampicin. }\end{array}$ & $\begin{array}{l}\text { Dexamethasone, } \\
\text { Erythromycin, } \\
\text { Verapamil. }\end{array}$ \\
\hline $\begin{array}{l}\text { OCT1, } \\
\text { OCT2, } \\
\text { OCT3. }\end{array}$ & $\begin{array}{l}6 q 26 \\
6 q 26-27\end{array}$ & $\begin{array}{l}\text { Hepatocyte, } \\
\text { Kidney, placenta, } \\
\text { enterocytes. }\end{array}$ & $\begin{array}{l}\text { Acyclovir, gancyclovir,metformin, } \\
\text { cimitidine, tyramine }\end{array}$ & $\begin{array}{l}\text { Acebutolol, } \\
\text { Midazolam, } \\
\text { Verapamil, } \\
\text { Prazosin, } \\
\text { Procainamaide }\end{array}$ \\
\hline
\end{tabular}

MDR: Multi-drug resistance, MRP: Multi-drug resistance-associated protein, OATP: organic anion-transporting polypeptide, OCT: Organic cation transporter, P-gp: P-glycoprotein. 
P-gp (ABCB1)
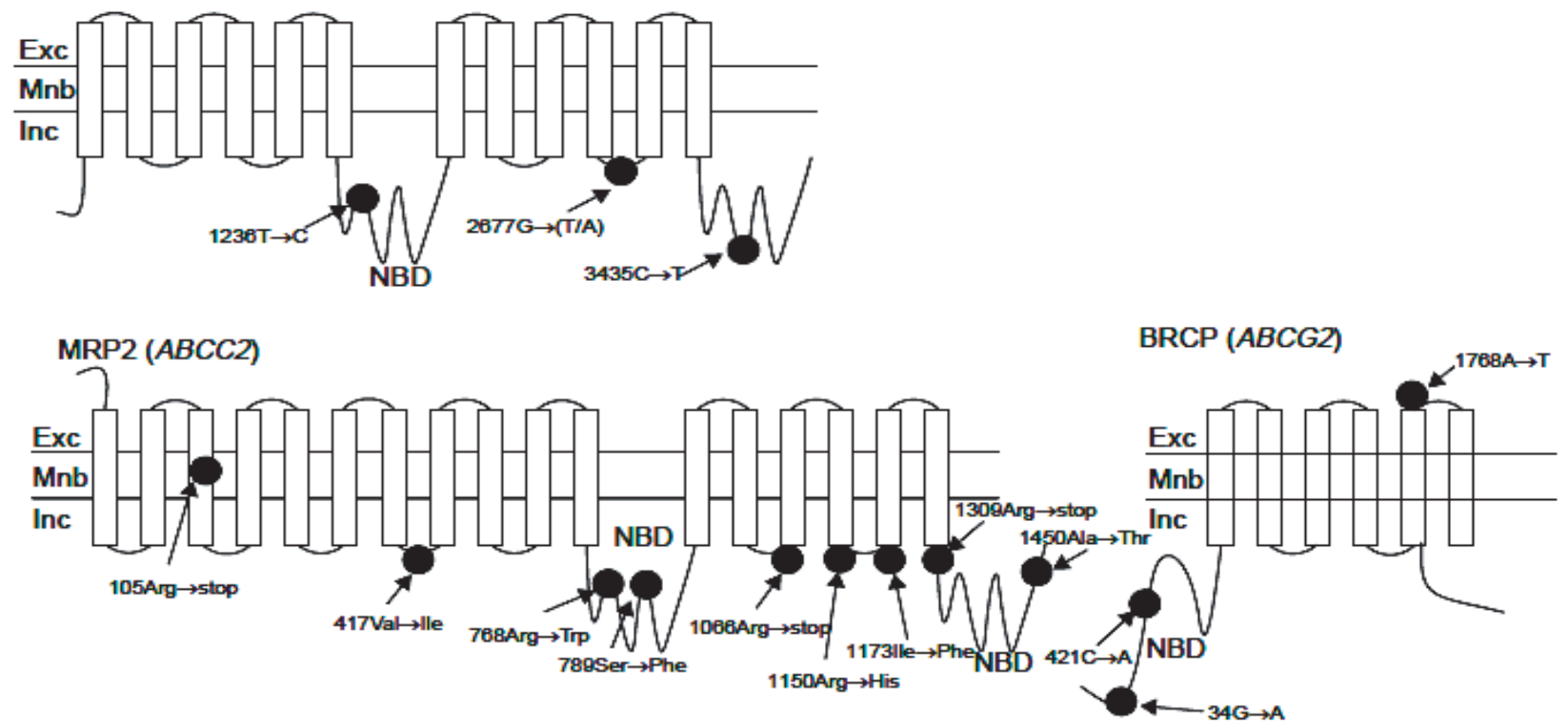

Figure 4: Schematic representation of secondary structures in ABC drug transporters showing nucleotide substitutions. ${ }^{27}$

OATPS

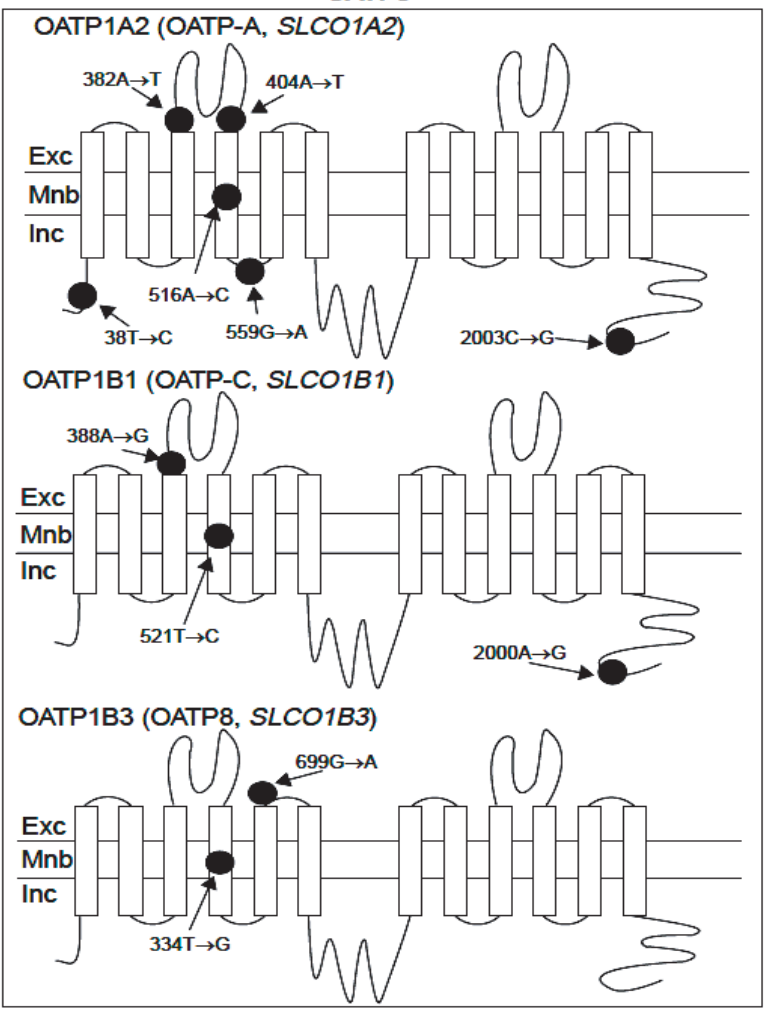

Figure 5(a)

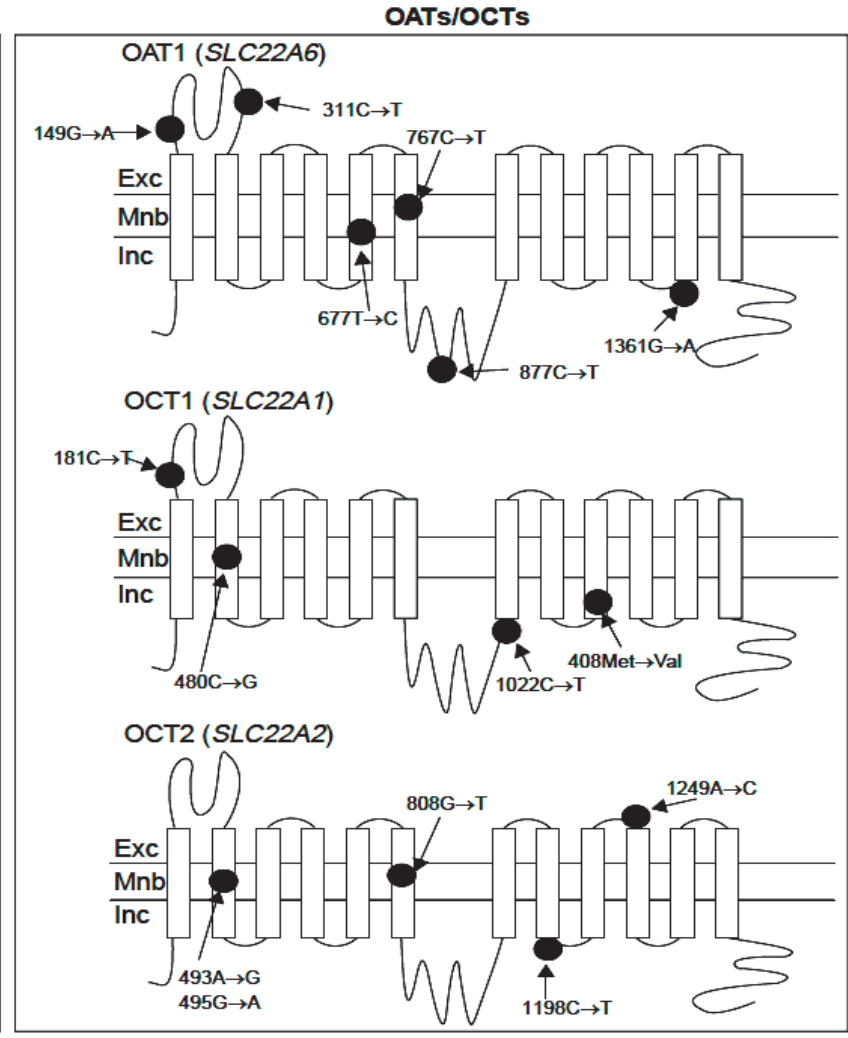

Figure 5(b)

Figure 5(a) \& 5(b): Schematic representation of secondary structures in drug transporters showingnucleotide substitutions. ${ }^{27}$ 


\section{Polymorphisms of transporters in different ethnic populations}

Ethnic variation in the frequency of drug transporters can be a promising factor for justifying pharmacotherapy. The table below is meant to show the ethnical variation in the transporter genes which can possibly be an evidence for the pharmacogenetic polymorphism altering therapeutic efficacy. As mentioned in the genetic variation in metabolic enzymes above that different races show phenotypic and genotypic variation and the resultant altered therapeutic profile, the table below is to subside the same notion of therapeutic variation. For an example, It has been reported that there are inter-ethnic variations are present in the frequencies of PMs of CYP2C19; that is $2.5 \%$ in white Americans, $2 \%$ in African Americans, $3.5 \%$ in White Europeans, $4.8 \%$ in shona Zimbabweans, $19.8 \%$ in the Chinese-Han population, $13.4 \%$ in ChineseBai population, $12.6 \%$ in Korean and $18-22.5 \%$ in the Japanese populations. ${ }^{20}$ So, this people will respond differently to a specific recommended dose of drug and drug metabolism will also differ from normal people.

\section{Impact of transporter polymorphism on pharma- cotherapy}

\section{Pharmacokinetic and Pharmacodynamic conse- quences:}

The genetic polymorphism of transporters have shown to alter the pharmacokinetic parameters such as area under the curve (AUC) and maximum plasma concentration (Cmax) those are the major determinants of pharmacotherapy. Thus, changes in AUC and Cmax can lead to potential therapeutic failure or toxicity in narrow therapeutic index drugs such as phenytoin, digoxin. ${ }^{5}$

Studies also suggests that pharmacogenetic polymorphism is also associated with pharmacodynamic consequence of $A B C B 1$ gene polymorphism for HIV drugs, antiepileptics, chemotherapy, P-gp substrates (immunosuppresants and tricyclic antidepressants), and others. Most of them are associated with response other than needed.

\section{Pharmacogenetic polymorphism in drug targets}

Most drugs show their effect through drug targets such as receptors, ion channels including enzymes and many of the drug targets bear polymorphism leading to altered therapeutic response. ${ }^{8}$ Genetic polymorphism of drug targets can be an important and interesting function for therapeutic efficacy.

Studies done on $\hat{a}_{2}$-adrenoreceptor (coded by ADRB2 gene) illustrates link between genetic polymorphisms in drug targets and clinical responses. ${ }^{28}$ Single-nucleotide polymorphism in ADRB2 resulted in altered signal transduction. Studies ${ }^{28}$ done on agonist-mediated vasodilation and desensitization with isoproterenol in one genotype (homozygous for Arg at ADRB2 codon 16) showed nearly complete densitization and significant reduction in venodilation whereas in another genotype (homozygous for Gly at ADBR2 codon 16) no significant change in venodilation was seen. Studies on genetic polymorphism and long term regular inhalation therapy of â-agonist showed different influence of those drugs in genotype-showing risk (deleterious or nonbeneficial effects) to codon 16 Arg/Arg genotype in terms of therapy, suggesting alternative therapy or earlier initiation of antiinflammatory agents, or both. ${ }^{28}$

Study conducted by Evans \& Johnson ${ }^{29}$ on clonazipine response and polymorphism (including aadrenergic receptors, dopamine receptors, serotonin receptors, histamine receptors and serotonin transporters) in schizophrenic patients showed significant predictive values (76\% positive, $81 \%$ negative) and sensitivity (96\%) in identification of the patients with improvement with clonazipine and $38 \%$ specificity in identification of the patients with minimal response to the drug.

\section{Pharmacogenetic based diagnostics (PGDx) in therapeutic decision making}

The consequences of polymorphism in drugmetabolizing enzyme, drug transporters and drug targets were explained above. Most of the consequences were a mixed bag of ineffectiveness and toxicity. As simple as to understand the drug is not within the therapeutic index. PGx has brought up the reasons of failure of therapy and it is the PGx itself that can help in success of therapy. All is needed is to put some brains to make it work. A key factor in PGDx in therapeutic decision making that can assist, in part, is the appropriate dose adjustment of drug, where genetic polymorphism can lead to major changes in pharmacokinetic parameters. ${ }^{5}$

Kirchheiner et $\mathrm{al}^{5}$ have illustrated the role of dose adjustment in therapeutic decision making with theoretical drug example that is supposed to be a substrate of genetically polymorphic enzyme CYP2D6. The theoretical standard dose was taken with relevant assumptions and the illustration has been depicted in the graph below.

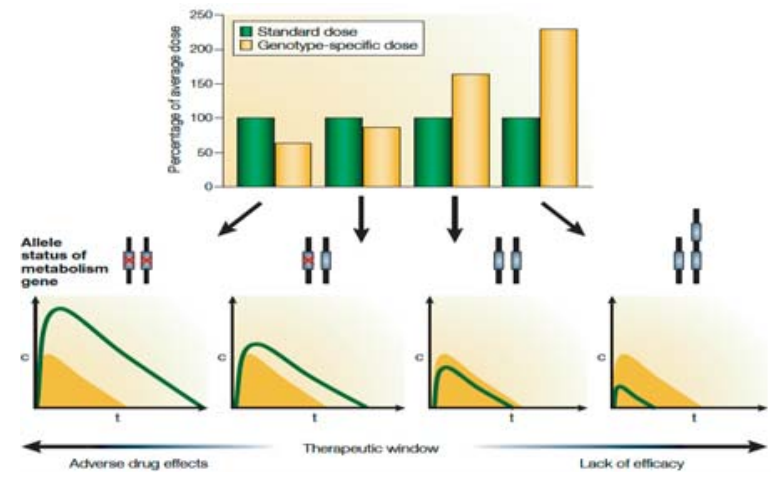

Fig.-6: Illustration of the role of dose adjustment in therapeutic decision making with theoretical drug example. ${ }^{5}$ 
The AUC in different alleles (UMs=Ultra Metabolizers, EMs=Extensive Metaboilizers, IMs=Intermediate Metabolizers and PMs=Poor Metabolizers) were compared with each other and also with standard. AUC for UMs, EMs, IMs and PMs were 50, 100, 150 and 200 units giving a linear relationship between number of active alleles of a drug metabolism gene and extent of drug clearance, typical to many antidepressants. ${ }^{5}$ According to the AUC values the PMs should receive one quarter of dose that is administered to UMs. Dose adjustment is therefore essential to produce good therapeutic efficacy, equalizing AUC and Cmax would be the main aim (principle of bioequivalence). Dose adjustment according to genotype can help in achieving uniform drug exposure which can indeed prevent drug toxicity as well as therapeutic failure in cases like depression, cancer. ${ }^{5}$ However, genotypic data on many drugs are not available which could help in more precise decision making by dose adjustment. ${ }^{5}$

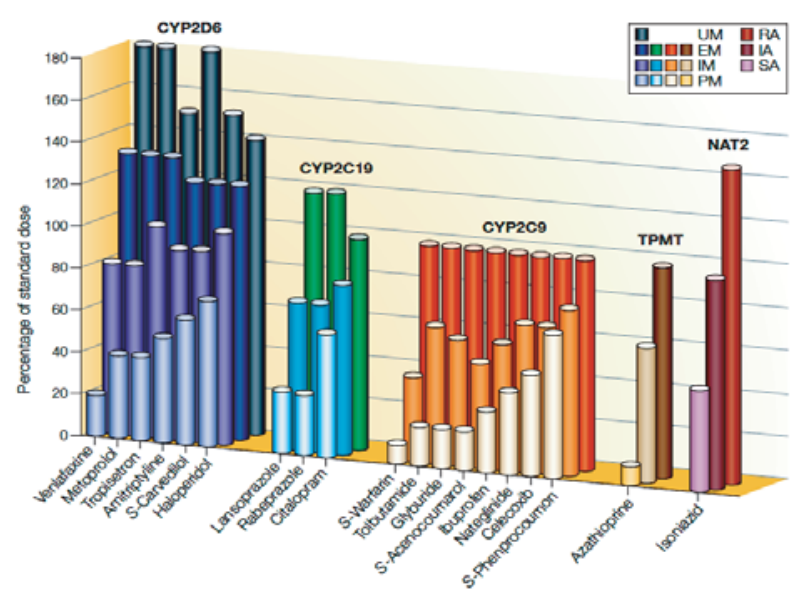

Figure 7: Examples of dose adjustments based on PGDx. The impact of genetic polymorphisms in CYP450 enzymes CYP2D6, CYP2C19 and CYP2C9, thiopurine S-methyltransferase (TPMT) and N-acetyltransferase type 2 (NAT2) based on the difference in pharmacokinetic parameters from clinical studies. $30-33,5$ The dose adjustments in the graph are based on differences in dose-related pharmacokinetic parameters (clearance, AUC, steady state concentration) caused by particular genotypes. ${ }^{5}$

\section{CONCLUSION}

Pharmacogenetic polymorphism can be a useful marker for understanding the variation in pharmacokinetics and pharmacodynamics of drugs that have narrow therapeutic index as well as are clinically useful. The approach can be applied in the early stage of drug development as well as in clinical praxis. The nascent approaches to pharmacotherapy from the perspective of pharmacogenetic polymorphism seem lot more promising. However, there are still many loop holes to be buried before revolutionising the treatment protocol persisting since long time. There is a need to develop concrete methodology for in-vitro to in-vivo correlation. The pros of the newer approaches still need more justification and there may be more cons still waiting. The success of pharmacogenetics can be charismatic for risk assessment of an individual against a particular drug. It seems there will be no therapeutic failure of drug as far as correct way is followed because the concept of pharmacogenetics based on polymorphism is systematic, scientific and more importantly evidence based. But discovery for goodness has not always proved good for mankind. Strict guiding laws, rules and regulation are critically important. There is always a fear for unpredicted misuse. Biomedical databases need to be very confidential. There is also a necessity of professional experts to handle pharmacogenetic approaches not only in theories but also in practice.

\section{REFERENCES}

1. Spear BB, Heath-Chiozzi M, Huff J. Clinical application of pharmacogenetics. Trends Mol Med. 2001; 7: 201-204.

2. Rubin DL, Thorn CF, Klein TE, Altman RB. A statistical approach to scanning the biomedical literature for pharmacogenetics knowledge. J Am Med Inf Asso. 2005; 12: $121-129$.

3. Garten $\mathrm{Y}$, Altman RB. Pharmspresso: a text mining tool for extraction of pharmacogenomic concepts and relationships from full text. BMC Bioinformatics 2009; 10: S6.

4. Norton RM. Clinical pharmacogenomics: applications in pharmaceutical R\&D. DDT. 2001; 6: 180-185.

5. Kirchheiner J, Fuhr W, Brockmoller J. Pharmacogeneticsbased therapeutic recommendations - ready for clinical practice? Drug Discovery 2005; 4: 639-647.

6. Omari AA, J. Murry DJ. Pharmacogenetics of the cytochrome P450 enzyme system: review of current knowledge and clinical significance. J Pharm Prac. 2007; 20:206-218.

7. Nagasubramanian $R$, Innocenti $F$, Rat MJ. Pharmacogenetics in cancer treatment. Ann. Rev. Med. 2003; 54: 437-452.

8. Meyer UA. Pharmacogenetics and adverse drug reactions. Lancet 2000; 356: 1667-1671.

9. Ayrton A, Morgan P. Role of transport proteins in drug discovery and development: a pharmaceutical perspective. Xenobiotica 2008; 38:676-708.

10. Endres $\mathrm{CJ}$, Hsiao P, Chung FS, Unadkat JD. The role of transporters in drug interactions. Euro J Pharma Sci. 2006; 27: 501-517. 
11. Muzuno N, Niwa T, Yotsumoto $\mathrm{Y}$, Sugiyama $\mathrm{Y}$. Impact of drug transporter studies on drug discovery and development. Pharma Rev. 2003; 55: 425-461.

12. Evans WE, Relling MV. Pharmacogenomics: Translating functional genomics into rational therapeutics. Science. 1999; 286: 487-491.

13. Ingelman-Sundberg M, Sim SC, Gomez A, RodriguezAntona C. Influence of cytochrome $\mathrm{P} 450$ polymorphisms on drug therapies: Pharmacogenetic, pharmacoepigenetic and clinical aspects. Pharma \& Ther. 2007; 116:496-526.

14. Rettie AE, Jones JP. Clinical and toxicological relevance of CYP2C9: drug-drug interactions and pharmacogeetics. Ann Rev. Pharmacol. Toxicol. 2005; 45: 477-94.

15. Aithal GP, Day CP, Kesteven PJL, Daly AK. Association of polymorphisms in the cytochrome P450 CYP2C9 with warfarin dose requirement and risk of bleeding complications. Lancet 1999; 353: 717-719.

16. Ensemble Genome Browser. Available at http:// www.ensembl.org/index.html. [Accesed July 5, 2009]

17. Lee CR, Goldstein JA, Pieper JA. Cytochrome P450 2C9 polymorphisms: comprehensive review of the in-vitro and human data. Pharmacogenetics 2002; 12: 251-263.

18. Ali ZK, Kim RJ, Ysla FM. CYP2C9 polymorphisms: Considerations in NSAID therapy. Cur Opi Drug Disc Dev. 2009; 12: 108-114.

19. Kalow W. A pharmacogeneticist's look at drug effects and the drug development process: an overview. Expert Opin. Pharmacother. 2005; 6: 1299-1303.

20. Furuta T, Shirai N, Sugimoto M, Nakamura A, Hishida A, Ishizaki T. Influence of CYP2C19 pharmacogenetic polymorphism on proton pump inhibitor based therapies. Drug Metab. Pharmacokinet. 2005; 20: 153-167.

21. Wilkinson GR. Drug metabolism and variability among patients in drug response. N Engl J Med 2005; 352: 22112221.

22. Desta Z, Zhao X, Shin JG, Flockhart DA. Clinical significance of the cytochrome P450 2C19 genetic polymorphism. Clin Pharmacokinet. 2002; 41: 913-958.
23. Wedlund PJ. The CYP2C19 enzyme polymorphism. Pharmacology 2000; 61: 174-183.

24. Klotz U. Clinical impact of CYP2C19 polymorphism on the action of proton pump inhibitors: a review of a special problem. Int J Clin Pharmacol Ther. 2006; 44: 297-302.

25. Ingelman-Sundburg $M$, Rodriguez-Antona $C$. Pharmacogenetics of drug-metabolizing enzymes: implications for a safer and more effective drug therapy. Phil Trans R Soc B. 2005; 360: 1563-1570.

26. Ingelman-Sundburg M. Pharmacogenetics of cytochrome P450 and its applications in drug therapy: the past, the present and future. Trends Pharmacol Sci. 2004; 25: 193200.

27. leiri I, Takane H, Hirota T, Otsubo K, Higuchi S. Genetic polymorphisms of drug transporters: pharmacokinetic and pharmacodynamic consequences in pharmacotherapy. Expert Opin. Drug Metab. Toxicol. 2006; 2: 651-674.

28. Evans WE, McLeod HL. Pharmacogenomics - drug disposition, drug targets, and side effects. In: drug therapy (Wood, A. J. J., ed.) N Engl J Med. 2003; 348: 538-549.

29. Evans WE, Johnson JA. Pharmacogenomincs: the inherited basis for interindividual differences in drug response. Annu. Rev. Genomics Hum. Genet. 2001; 2: 9-39.

30. Kirchheiner J. et al. Pharmacogenetics of antidepressants and antipsychotics: the contribution of allelic variations to the phenotype of drug response. Mol. Psychiatry 2004; 9 : 442-473.

31. Kirchheiner J. et al. CYP2D6 and CYP2C19 genotypebased dose recommendations for antidepressants: a first step towards subpopulation-specific dosages. Acta Psychiatr. Scand. 2001; 104: 173-192.

32. McLeod HL, Siva C. The thiopurine S-methyltransferase gene locus- implications for clinical pharmacogenomics. Pharmacogenomics 2002; 3: 89-98.

33. Brockmöller J, Kirchheiner J, Meisel C, Roots I. Pharmacogenetic diagnostics of cytochrome P450 polymorphisms in clinical drug development and in drug treatment. Pharmacogenomics 2000; 1: 125-151. 